\title{
La filosofía en el arte de Frida Kahlo. La colisión de mestizajes en América como interpelación de lo urbano.
}

\author{
The philosophy in Frida Kahlo's art. The collision of miscegenation in America \\ as an interpellation of the urban.
}

Recibido: mayo/2018

Aceptado: agosto/2018

\section{Resumen}

La colisión cultural expresada en los autorretratos de Frida Kahlo es algo que América vive filosóficamente entre el Estar y el Ser. Lo precolombino rodea a la civilización europea como "espacio vital indeterminado" con un horizonte contingente, confundiéndose con la barbarie vegetal. Lo salvaje se presenta de un modo inminente. No hay belleza sino una inmensidad sublime, a punto de caer sobre la cultura urbana dentro de una dialéctica entre lo bárbaro y lo civilizado. De acuerdo con el pensador argentino Rodolfo Kusch en América el espacio vital anterior a la llegada europea o primer mestizaje no ha sido superado, acecha al segundo mestizaje Americano a partir del contacto con Europa. Corresponde a una ontología del "Estar" que siempre vuelve a presentarse. No es un estadio superado sino que acecha constantemente a la ciudadanía. La colisión entre el primer mestizaje y el segundo mestizaje se mantiene actualmente. Se introduce en aspectos urbanísticos que muestran la ambigüedad americana. Frida Kahlo da cuenta de esta ambigüedad a través del arte como interpelación de lo urbano. Su rostro persevera estable en un modo de ser europeo, en cambio su cuerpo se reentrama con el primer mestizaje. En la obra "Autorretrato en la frontera" se muestra el contraste entre esos dos mestizajes que, aunque parecen separados como lo civilizado y lo bárbaro, no obstante mantienen una conexión.

\section{Palabras Clave:}

Mestizajes; Kahlo; Kusch; Urbano; Filosofía del arte.
Aldo Enrici ${ }^{1}$

\begin{abstract}
The cultural collision expressed in Frida Kahlo's self-portraits is something that America lives philosophically between Estar and Ser. The pre-Columbian surrounds European civilization as "indeterminate vital space" with a contingent horizon, confusing itself with vegetal barbarism. The wild appears in an imminent way. There is no beauty but a sublime immensity, about to fall on the urban culture within a dialectic between the barbarian and the civilized. According to the Argentine thinker Rodolfo Kusch in America, the vital space prior to the European arrival or first miscegenation has not been surpassed, stalking the second American miscegenation from contact with Europe. Corresponds to an ontology of "Being" that always comes back. It is not a surpassed stadium but it constantly stalks the citizens. The collision between the first miscegenation and the second miscegenation is currently maintained. It is introduced in urban aspects that show the American ambiguity. Frida Kahlo gives an account of this ambiguity through art as an interpellation of the urban. His face perseveres stable in a European way of being, however his body is reentrawed with the first miscegenation. In the work "Self-portrait on the border" shows the contrast between these two mestizajes that, although they seem separate as the civilized and the barbaric, nevertheless maintain a connection.
\end{abstract}

\section{Keywords:}

Miscegenation; Kahlo; Kusch; Urban; Philosophy of art.

\footnotetext{
${ }^{1}$ Adscripción: Universidad Nacional de la Patagonia Austral, Argentina. Doctor en filosofía, área: hermenéutica. aenrici@uarg.unpa.edu.ar
} 


\section{Ambivalencia entre Ser y Estar.}

El pensador argentino Rodolfo Gunter Kusch piensa América desde la dialéctica entre el Estar y el Ser. Si bien no es un filósofo tan difundido, su recorrido intelectual lo lleva a que muchos de los actuales intelectuales reconozcan una especial filosofía, de formación europea, pero de "americanización" inusitada. Kusch maneja la lengua alemana a partir de ser hijo de inmigrantes. Ayudó en las traducciones a notables filósofos mientras fuera estudiante. Leyó a Heidegger y, en esta lectura se dio cuenta de que el Dasein se aproximaba al Estar, que Kusch posteriormente establecerá como concepto fundamental de la vida americana. Por otra parte, su idea de mestizaje es particular. Hay mestizaje en América antes de la llegada de los europeos, quienes producirán un segundo mestizaje carnal, muchas veces forzado. Un primer mestizaje sin violencia, de mezcla espontánea entre los componentes vitales del paisaje. Ese mestizaje corresponde al Estar y, no ha sido superado por el segundo mestizaje. Permanece alerta en América como dialéctica entre el Ser y el Estar. Asoma en ocasiones. Su aparición tiene las características de irrumpir en la "ficción urbana" de tradición Europea, identificada con el Ser. Frida Kahlo es una de las artistas que con más acierto muestra la constitución del primer mestizaje.

Rodolfo Kusch define el "Estar" como estructura existencial y cultural americana. En otras palabras, mientras "Ser" precisa y hace referencia a la esencia, el concepto "Estar" señala y ubica a un ente en una situación particular (alguien está sentado). Kusch distingue entre Ser y Estar. Ser, o "ser alguien", es un concepto propio de la actividad burguesa de la Europa. Estar es considerado como una modalidad profunda de la cultura precolombina (Kusch, 1962: 7). Nuestro vivir real implica una "decisión a tomar" entre el ser y el Estar, pero aún y siempre sin realizarse. Una decisión que no ha de tomarse, que constituye nuestra autenticidad americana actual. La teoría decolonial mantiene una cercanía con el pensamiento de Kusch. Se reconoce su impacto en la teoría decolonial por medio del concepto de "pensamiento fronterizo" (border thinking). Kusch intenta pensar filosóficamente desde las "ruinas" de las categorías indígenas de América (Mignolo, 2010). La teoría decolonial posiciona a Kusch mediante el concepto de "conciencia de inmigrante" (inmigrant consciousness), que contiene el caso de la filosofía europea arribada al contacto con América (Viveros Espinosa, 2016).

En cuanto al Dasein que Heidegger enuncia para delimitar al hombre en su etapa existenciaria de Ser y Tiempo tiene similitud con el Estar de Kusch, aunque para éste, el "Estar" es seminal. El Estar yace en el origen y no en el final de una larga tradición, como Heidegger encuentra en la filosofía europea. El Dasein es traducido como "ser ahí", con el sentido de un "mero Estar", de desnudo "darse", aunque en lengua alemana no hay verbo "Estar". El Ser es una forma de expresar lo real que remite a lo esencial (lo que permanece) en la filosofía europea. Heidegger postula su $D a$ sein como condición del Ser en una época que es considerada como final de la historia de la filosofía, presuponiendo una historia filosófica anterior dedicada netamente al Ser (Heidegger, 1963). La fenomenología que Heidegger hace del Dasein indica que tomó como objeto al "uno anónimo" (das Man) que simplemente está (Kusch, 2003: 109-110). La barbarie americana mantiene semejanza con el "Estar" como noción clave y necesaria para la dialéctica con otra noción, la civilización que mantiene semejanza con el ser, lo permanente, lo esencial. La barbarie es entendida desde el romanticismo como una etapa a sortear para aquellos que esperan progreso y civilización (Corbetta, 2014). La barbarie para Kusch no forma parte de una etapa, sino más bien de una dialéctica sin resolver. Pero también esa dialéctica entre una civilización impuesta, por un lado, frente a la fluidez compleja de "la barbarie" prexistente conforman un devenir que no se puede distinguir en términos de orden y caos. Desde este sitio puede definirse lo complejo de América. Pese a que desde América, en muchas situaciones nos acercamos más a una de las actitudes (civilización, ciudad, acción) que a otra (tierra, inconsciente, inacción) ello no significa que la barbarie sea una etapa superada. $\mathrm{La}$ barbarie es una característica americana. Hay un contrapeso que "encarna una realidad muy honda, que hace que sus contrarios -la conciencia, la acción y la razón- [...] manifiesten sus estructuras ficticias al menor análisis" (Kusch, 2007: 22). El "Estar" rodea la civilización como inmensidad sublime. Desde el punto de vista estético la obra de Frida Kahlo muestra en sus autorretratos una convivencia ambigua entre mestizajes, donde un primer mestizaje correspondiente a una barbarie vegetal y precolombina protege el cuerpo dañado por la civilización urbana del segundo mestizaje. 


\section{Hermenéutica como posibilidad ontológica.}

La hermenéutica, con su afán de comprensión integradora hace posible interpretar la obra de Frida Kahlo desde una concepción ontológica. Puesto que no necesitamos de la vida de la artista para hacer de su arte una expresión digna de la lectura filosófica. Consideraremos dos hermenéuticas americanas. Por un lado la hermenéutica analógica, encabezada por Mauricio Beuchot y la hermenéutica pragmática, que ha sido expuesta por Richard Rorty.

Desde la hermenéutica analógica de Mauricio Beuchot la analogía siempre propone, al menos, un "hilo común" entre ambos lados (Beuchot, 2005). Es interesante cómo esos hilos también se manifiestan en Frida Kahlo pictóricamente entre las raíces (los cables, las capilaridades) que se conectan de diferentes modos como en el espacio subterráneo en "frontera entre las dos naciones" o entre su cuerpo y el paisaje precolombino. El hilo de la hermenéutica analógica ha ha permitido la disminución de la violencia y el desarrollo de la comprensión hacia los indígenas en la época de la conquista. Dentro de la analogía la solidaridad traspasa la realidad cotidiana pero sin descartarla para entrar en la alteridad, el Estar, que se emparenta al "ser analógico" en Beuchot. Por ahora, la hermenéutica de América se mantiene entre el Estar y el Ser, es decir, en la alteridad leve, rara e indefinida, queer, no tan extremos como a fines del siglo XX, tan lingüísticos y tan antiontológicos (2003: 166-173). La analogía ha permitido la comprensión de la posibilidad de un "cristianismo americano" distinto al cristianismo conquistador. La hermenéutica analógica, a su vez, hace posible una comprensión por parte de nuestros americanos de los errores eurocéntricos, tal cual ocurre en la pintura de Frida Kahlo. La comprensión de injusticias no es la aceptación callada sino un esfuerzo solidario para asimilar la falta de tolerancia analógica o exceso de univocidad en la "racionalidad moderna" y la generación de argumentos para permitir un pensamiento inclusivo.

Por otra parte la interpretación analógica nos permite considerar al artista y a la obra de manera separada y relacionada. En este sentido existe un distanciamiento de la hermenéutica analógica respecto a la romántica y psicológica. Beuchot, por el contrario, sin negar la importancia que tie- ne el autor en dicho proceso, no ve en la obra un puente para llegar al artista. Para la obra de Frida Khalo, de acuerdo a posición mencionada nos permite que no sea necesario conocer su intención. El texto no es una disculpa para vincularse al autor. Por el contrario, la obra deja de ser un pretexto. La vida de Frida es excusa para llegar a la esteticidad. (Hernández Otañez 2016). Aunque nos movemos de modo analógico, buscando similitudes, parecidos, pero somos estudiados de modo digital, como bases de datos, haciendo de lo analógico algo equívoco. La barbarie "vuelve a nosotros la realidad profunda" como instintiva "tentación" de vuelta al vacío acogedor. Hay que aceptarla con valor, para que deje de perturbarnos o para aceptar su presencia, lo cual queda de manifiesto en la obra de Kahlo. América en Kahlo se presenta de modo dialéctico como arte crítico que reconoce la contención de un paisaje no conquistado, en debate con la construcción europeizante de lo ciudadano. América se encuentra escindida entre dos verdades; una ficticia encarnada en la ciudad y otra real encarnada que suele reaparecer en el reverso de nuestra vida ciudadana como una verdad más intensa que esta urdimbre racional que traemos de afuera (Kusch, 2007: 19). Detrás de la imagen de orden racional de la ciudad aguarda un tejido territorial colmado de abismos desde donde sólo es certeza el "aquí y el ahora". Lo caótico americano como el extremo de equivocidad en la semejanza ha permitido realizar vinculaciones con el pensamiento europeo unívoco que se había vuelto univoco. El primer mestizaje vigila incesantemente lo urbano. Nos asalta, y ofrecemos resistencia, con el rostro inexpresivo que nos muestra Kahlo. Resulta conveniente hablar de la imagen sublime que aflora con fuerza territorial, que solemos identificar con el paisaje del mar, la selva o el desierto. Entre la vida de ficción que "percibimos" en el paisaje urbano, cuya belleza disfrutamos, -edificios, tecnología digital, diseños, "apenas alcanzamos a vivir" la verdad como un fondo que vuelve a encontrarse con el ser ciudadano, al que llamamos "el Estar". Nos encontramos cobardemente en un estado de indecisión montado sobre un constante remolino hasta que la barbarie reaparece, entre el ser armonioso de la ciudad y el Estar indiferenciado vegetal.

Desde la hermenéutica pragmática norteamericana de Richard Rorty (1989) se puede decir que la solidaridad tiene un carácter comprensivo a partir de reconocer la ampliación del nosotros 
en otredades a partir de sus propios sufrimientos cuando nos condolemos del mismo. Rorty explica su idea de la verdad como creación solidaria a partir de la concepción pragmatista del lenguaje de Donald Davison y Ludwig Wittgenstein, según el cual el mundo sólo lo hacemos nosotros, (Rorty, 1989: 26). Las descripciones del mundo no son verdaderas o falsas pues éstos son atributos que sólo se pueden predicar de proposiciones lingüísticas o artísticas. La solidaridad es un sentimiento de compasión con aquellos que en algún momento se asemejan a lo que nosotros podemos captar como dolor o sabiduría. El concepto de «nosotros» tiene un sentido propio y no equivale a «toda la humanidad», sino que depende de semejanzas que nos gustaría incorporar a nuestra cultura en la forma de nuevos mestizajes. No hace falta encontrar una esencia común a la raza humana, el reconocimiento de que hay una característica cultural que podemos incorporar a nuestra vida es bastante para una filosofía pragmatista. Nos hace entender que las personas dan sentido a su vida a través de dos modos de contextualización o mestizajes: a través de la relación con otras personas y con la comunidad (aspiración horizontal de solidaridad)- o, a través de la relación con objetos no comunitarios (la verdad o Dios) (aspiración de vertical objetividad). El pensamiento filosófico occidental se ha guiado por el apetito de objetividad. Ha tratado de fundamentar las prácticas y las instituciones sociales en relación con la esencia del ser humano o de la naturaleza, habiendo logrado una mejor convivencia cuando se piensa en logros comunitarios (Rajchman, 1985: 3-19). Es oportuno interpelarnos por la convivencia entre ambos modos mestizajes tal como creemos que proponen, cada uno a su manera, Kusch y Rorty.

\section{Barbarie americana.}

La barbarie en América se presenta de un modo inminente. Ya no hay belleza sino una inmensidad que llamaremos sublime, a punto de caer sobre la cultura civilizada, al modo de acechanza. Desde la Ilustración se denomina a esta condición como "barbarie", para denotar la carencia de civilización. Robert Hullot-Kentor (2010) procura entender la actual "barbarie civilizada". Tiene presente que este estado actual de civilización es la verdadera barbarie. La barbarie no es resultado del retraso cultural o tecnológico, como supusieron otros europeos que vinieron a América, desde artistas hasta religiosos, sino del progreso mismo. La paradoja de la Ilustración se mantiene en esa línea, en la que para liberarse de aquellas amenazas mitológicas, el hombre ensanchó su dominio, generó medios de sumisión más poderosos que nunca, con los cuales ejerció el sometimiento. Vivimos la era más catastrófica de toda la historia de la humanidad, de toda la historia natural, y somos incapaces de saber qué está pasando. Tenemos la habilidad de convertir cualquier cosa en un arma y no podemos dejar de hacerlo (Hullot-Kentor 2010: 5). Con idéntica desconfianza hacia la ficción racional de lo civilizado, Rodolfo Kusch propone que nos sumerjamos en lo popular para alejarnos del mito de la civilización urbana. Para lograr esto, tenemos que dar un "salto atrás" que nos permita, paradójicamente, adelantar. Ese salto hacia lo popular, dice, es "un salto hacia lo embrionario filosófico" (Kusch, 2000: 13). El mestizaje americano no se inicia con la conquista, sino que es originario, viene de la época precolombina, amenazando transformar nuestra ficción europea en una realidad cruelmente autóctona" (Kusch, 2000: 22). El primer mestizaje, se manifiesta en el demonismo de la tierra expresado en la comunidad de la selva pre-paisajística indeterminada, en el sentido de no ser aun percibida culturalmente ni superada por el segundo mestizaje. Encontramos este primer mestizaje en la figura de la "serpiente emplumada" que, constituye para el filósofo "un momento de la vida americana" o de la ambigüedad originaria conformada por la fusión entre el vuelo de lo espiritual y la vitalidad que se desplaza sin soltarse de la tierra. El mito de la serpiente emplumada como modo de colisión vital, -el Quetzalcóatl-, manifiesta la ambigüedad inherente a la condición de un primer mestizaje americano, siempre presente en el tradicional segundo mestizaje, marcado por la llegada europea: la "serpiente" es cuerpo físico con las restricciones propias de una transición. Las "plumas" llevan los principios espirituales que precisan un asentamiento. No existe una separación sino una constitución fantástica. En Europa, según Hannah Arendt, desde el momento de su fundación, el territorio ciudadano se encuentra ligado a un carácter sacro. Una vez fundado conserva su valor para todas las generaciones futuras, el territorio restante es parte de una ciudad central e imperial. El compromiso político significa la custodia de la fundación de 
la única ciudad. Esa ciudad fue por primera vez Roma. No se repetía la fundación de la primera polis, sino que se integraban territorios a la autoridad de los patres, (Arendt, 1956, 190-210). En América es discutible que haya sido así y, en este sentido, esa discusión es la que estamos llevando. La serpiente temeraria y el ave rapaz separadas y combatiendo entre sí, son ficciones posteriores a la serpiente emplumada, como si apareciera una discontinuidad o un fraccionamiento de este entramado animal originario del primer mestizaje. Lo ficticio ciudadano depende de lo fantástico del mestizaje que constituye una verdad que nos engendra como americanos. La ciudad americana será ficticia mientras no recupere la vegetalidad paisajística, al contrario de la voluntad romana.

\section{Interpelación pre-urbana.}

El arte de Frida Kahlo manifiesta una necesidad de reconocimiento de la territorialidad pre-urbana de su cuerpo, como nostalgia del primer mestizaje, tal cual observamos en la fusión con una naturaleza indiferenciada. Kahlo interpela lo urbano para verse a sí misma. Se multiplica en dos en algunas ocasiones, como si remitiera a un sinfín inicial, o a las dos versiones, la pre-urbana y la urbana, como si intentara recuperar el "Estar territorial" perdido.

Ser representación es ser imagen de algo. La imagen implica una naturaleza más remota. Alejados de un sentido ontológico existe una representación en un sentido político. La construcción del hombre ha girado en torno al ser filosófico. Pero la mujer ha girado en torno al concepto de alteridad, en cuanto territorio de dolor incomunicado del primer mestizaje frente a la llegada de la cultura patriarcal. Mientras Diego Rivera - esposo de Frida- ha mostrado cómo las paredes pueden ser soporte político del arte popular en los murales, Frida Kahlo ha mostrado cómo el cuerpo puede ser el soporte político de intervenciones estéticas femeninas. En América, antes del mestizaje con los europeos, la naturaleza se mostraba difícil de dominar, y tenía que pensarse la forma de mantenerse a salvo en ese medio. Rodolfo Kusch en su idea de que el primer mestizaje constituye una "barbarie vegetal", permite advertir un sentido que podemos definir como "femenino" del Estar correspondiente al primer mestizaje. Como indica Juan Cepeda, infiere esa cualidad estática en el sentido de Estarse ahí, con su comunidad, cultivando su parcela. El "Estar" es preexistente, como cualidad fundamental de esta cultura de la tierra, (2017: 133). La mujer ha sido insertada culturalmente en la categoría de otredad ontológica desde un inicio, como objeto sin trascendencia alguna (Domínguez, 2014, 60). La realidad femenina o el ser mujer es una construcción histórica al igual que la del hombre-varón, con un matiz altamente diferencial: su situación ha girado en torno a la alteridad. En el varón la construcción intenta evitar el miedo de perder las pocas cosas mantiene, ya se llamen ciudad, policía o próceres (Kusch, 2003. 15-16). La realidad femenina construye su Estar junto al paisaje, intentando entramarse en él.

Hasta aquí lo autóctono se compone de una ambivalencia o mestizaje originario que no implica humanidad o forma carnal humana en el sentido que lo será el segundo mestizaje, que se concentra en cuando el hombre impone su razón civilizante. El ave y la serpiente, son contrarios irreconciliables para la cultura ciudadana, pero se comportan en unidad cuando se mitologiza su vinculación. Esa capacidad de la ambivalencia es la que obliga a rastrear una ontología existencial en los escenarios que fueron negados (Cepeda, 2016). En los mitos europeos el Ser es anterior al Estar. En el sistema crítico de la filosofía de Frankfort la ilustración, presente en el mito de la astucia de Ulises, es interpelada en el uso de la razón instrumental, como paso hacia la dominación, fin último de toda empresa mágica lo mismo que científica. Ilustración y mito instrumental son, en lo relativo a su función, análogos al ser igualmente siervos del mismo fondo que prioriza el ser sobre el Estar: la voluntad de dominio. La Ilustración y su íntima relación con la ciudad quieren dominar a la Naturaleza a través de su arsenal conceptual pero no se da cuenta de que no existe tal cosa como la Naturaleza en primer lugar, si por ella entendemos un ente "puro" (Arriola 2013). No existe la "Naturaleza" si por ella entendemos algo dado perceptible diáfanamente por los sentidos. Hay un "Estar analógico" que no separa sino que entrelaza. De este modo toda ciudad es un mestizaje de lugares discernibles y otros indiscernibles que se reencausará (o perfeccionará) para perpetuarse como un atributo latente de lo autóctono en una segunda instancia o segundo mestizaje, lo cual compone una existencia oscilante del continente americano que atraviesa a lo largo de la historia. 
A partir de la oposición aparente entre vegetalidad (Estar) y carnalidad (ser) toda forma de vida se bifurca entre el Estar de lo estable (el ser) y el Estar de lo inestable (el Estar), entre lo que es y lo que no es, aunque sigue estando. El primer mestizaje no remite a una esencia pura y estricta, que mantienen lejanamente en oposición los extremos en que ya latiera el continente en la época precolombina. Lo europeo inserto en América se convierte en modelo de discriminación radiante al momento de la entrada filosófica de la alegoría de la caverna (Platón, 1997). Frente a las tinieblas americanas como modo pacífico de vida, que no están ni distinguen modos binarios a favor del "dualismo" europeo, el mito de la caverna nos encadena si no tenemos luz, sabiduría, claridad para discernir. Las sombras que aparecen reflejadas en la pared componen nuestra falsa realidad. No sabemos lo que nos aguarda, advierte el arte de Kahlo, renegando de la alegoría de la caverna. Lo importante es su cristalización existencial "al aquí y el ahora de nuestra vida cotidiana" que en América apunta "hacia abajo", (Ruvituso, 2017), hacia la tierra, hacia lo indefinible en su negación de la verdad adquirida por la ficción ciudadana. El primer mestizaje, no necesita de colisión con la cultura iluminada. Se sostiene sin sumisión como acecho permanente. Se expresa en la naturaleza indiferenciada, en una relación compleja. El ser humano no se diferencia en jerarquía de la piedra o los demás seres vivos. Pero cuando el mestizaje se reitera en un segundo conflicto, en este caso, el paisaje se erige como distinción limitada por la construcción de la ciudad que representa el proyecto civilizatorio de lo humano contra la naturaleza amenazante. No obstante esta primera América mestiza no nos abandona, sino que se filtra por siempre en la cultura ciudadana.

\section{Vegetalidad inicial como mujer.}

La situación de Frida Kahlo es particularmente considerado desde su arte. La mujer ha sido insertada en la categoría de "otredad" desde el inicio del segundo mestizaje, como parte de la barbarie desde la cultura civilizada. Reconocida como "la otra", ha permanecido indefinida Noelia Domínguez Romero (2014) como objeto desde una inmanencia equivalente al "Estar" territorial. La mujer pertenece al primer mestizaje como naturaleza verdadera. La realidad femenina o el ser mujer es una construcción histórica no equivalente a la del hombre-varón, pero con un matiz altamente diferencial: su situación ha girado en torno al concepto de alteridad (Domínguez Romero, 2014: 59-77). Frida Kahlo interpela mediante el arte para situarse en una recuperación territorial del mestizaje pre-urbano. Lo femenino debe a lo americano su modo de ser, que "se deja Estar", en condiciones preliminares a la fuerza varonil, que se manifiesta "siendo". En el autorretrato "Raíces", Frida "se deja Estar" reclinada sobre un paisaje resquebrajado, como un tronco cortado al que su sangre nutre. Por su plexo cruzan capilaridades vegetales que se trasponen entre sí y culminan en hojas de las que fluye su sangre como una planta fusionada con la parte más desértica de la Tierra. Su mirada se presenta frontal. En el torso aparece un vacío en el plexo abdominal como si fuera una ventana en el propio cuerpo. Los ramales que se van extendiendo para alimentar al pedregal desértico de fondo.

Figura 1. Raíces. 1943. Óleo sobre Metal. Dimensiones: 30'2 x 49'2 cm.

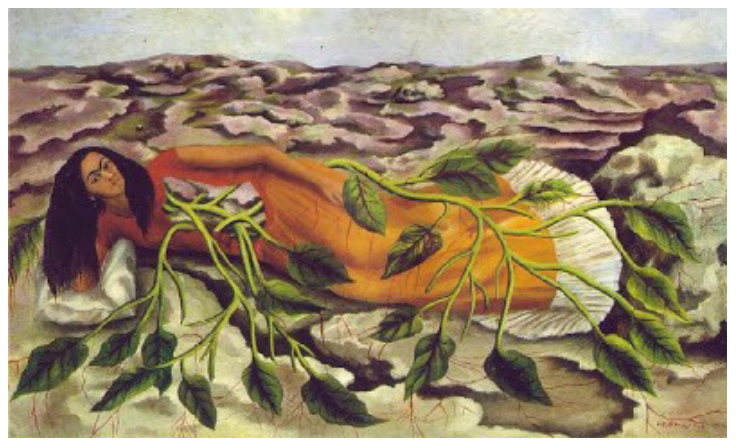

Fuente: Fotografia tomada por el autor.

Estar ahí, sin raíces verticales, como una ordenación horizontal de elementos que no sigue líneas de subordinación jerárquica sino que cualquier elemento puede afectar o incidir en cualquier otro (Deleuze y Guattari, 1972:13), rompe con la lógica dicotómica. Lo rizomático trepa horizontalmente, carece de unidad centrada. No existen puntos de ascenso aunque sí líneas interconectadas que se manifiestan en procesos (Fischer Pfaeffle, 2003). Retratándose a sí misma Kahlo se expone acostada en una superficie indeterminada, sin remedio, para ser abrazada por el paisaje. El cuerpo de Frida Kahlo se desanuda de la ciudad, como si volviera o quisiera reanudar aquel estado de vegetalidad inicial, de tenue salvajismo, infundida en el paisaje natural. En su produc- 
ción plástica hay una evidente dramatización y politización del cuerpo-rostro que está continuamente elaborándose, haciéndose y deshaciéndose (Domínguez Romero, 2014, 59). No solamente pinta para sí misma sino que pinta a "la mujer" que encarna al primer mestizaje. El rostro varonil permanece estático, sin expresión. Un semblante que manifiesta la colisión con el segundo mestizaje, o colisión con la civilización europea. Es el mismo rostro siempre, como si estuviera grabado para cada tela. Un rostro circunspecto, sin atisbos de imprudencia sino con una seriedad masculina enfriada. La manifestación facial acontece como contrapunto del cuerpo ávido de reanudamientos. Algo tan indolente no coincide con tantas destrezas corporales, no da cuenta de dolores ni de placeres. El rostro habla de la seriedad de Europa, del placer lánguido que ajeno a la barbarie. Una seriedad cínica correspondiente a los modelos de invasión colonial, al rigor de la física, de la econometría, del progreso y el rigor victoriano embebido en la revolución industrial, a la vez esnobista, como lo ha detectado la composición de Lawrence Alma-Tadema.Kahlo pinta para el interior de su cuerpo reclinado en el primer mestizaje. Vuelve a la vegetalidad americana de muchos modos con su cuerpo atravesado por un accidente ciudadano. Los críticos exaltan su resiliencia a través del arte. Abatida por la polio y por un brutal accidente de tránsito fue capaz de sobrevivir. Lo más notable de esta súbita ascensión del prestigio de la pintura de Frida Kahlo es la unanimidad en que se sustenta -la elogian los críticos serios y los frívolos, los inteligentes y los tontos. Los conservadores y antimodernos ven en ella una reminiscencia clásica entre los excesos de la vanguardia (Vargas Llosa, 2002). Pero Kahlo habla de América con el arte de modo filosófico, más allá de su sufrida vida.

\section{Autoexamen y rizoma.}

La obra pictórica de Frida Kahlo es sobre todo portadora de un sabio autoexamen. Su pintura no la describe, como podría ocurrir en los dibujos anatómicos, sino que intenta explicar las consecuencias estoicas que la enfermedad produce en su estado de ánimo (Amezcua, 2004). Sus autorretratos se amparan en el encuadre paisajístico precolombino, en su complejidad existencial. Cada autorretrato va transmitiendo la impotencia y la desesperación, mientras intenta explicarnos su padecimiento, la obra de Kahlo es víctima de la racionalidad urbana. Las víctimas no interpelan y cuestionan, enseñan la sabiduría popular latinoamericana elemental que frecuentemente nace de situaciones límite ante la injusticia en cada uno y en los otros. Frida establece con su pintura la "enfermedad en primera persona", es decir, cómo se siente en estado de sujeción urbana, o de qué modo hace saber que su interés es mostrarse en estadios sublimes, debatiendo con su estado de salud, llevándolo a la "enfermedad en tercera persona", (Amezcua, 2004) al conocimiento biomédico de la enfermedad, que Frida Kahlo exhibe en forma de instrumentos técnicos quirúrgicos agresivos, varoniles, como si fueran instrumentos de tortura. la pinza hemostática evita cruelmente que una de las Fridas siamesas se desangre en "Las dos Fridas" (1939). La enfermedad física aparece destacada por la Frida ciudadana, con un traje victoriano blanco, que permite resaltar aún más el corazón abierto y los vasos que terminan desangrándose sobre su regazo. La otra Frida aparece ataviada con el traje tradicional tehuano. Sostiene en sus manos un medallón con el retrato de Diego Rivera. No son dos Fridas, sino una misma, pero "ambiguada", sin decidir, dentro de la ambigua realidad americana en cada uno de los mestizajes. Una larga arteria une los dos corazones para dejar claro que son una misma. Entre la vida de ficción que "percibimos" en el paisaje urbano, la verdad real que "apenas alcanzamos a vivir" como un fondo que siempre vuelve a encontrarse con el ser ciudadano. Frida Kahlo se debate sin optar, entre Ser y Estar.

La familia de Frida no estaba de acuerdo con el casamiento con Diego Rivera. Decían que se trataba del encuentro de "un elefante con una paloma" (Artola, 2007: 182). La anterior metonimia acierta en el aspecto estético de ambos. Diego Rivera pinta desde adentro hacia afuera, de un modo expansivo y social. Frida Kahlo hace lo inverso. Pinta desde fuera -su invalidez- hacia adentro, de modo que pueda manifestar su espiritualidad interior (Artola, 2007). Pero también hace lo inverso políticamente. La realidad femenina en el caso de Frida es una construcción filosóficamente estoica, en permanente examen de sí misma, en permanente ejercicio para lograr espiritualidad. La espiritualidad no puede llegar a dar acceso a la verdad si no se está en condiciones, a través de una constante transformación del sujeto, (Fou- 
cault, 2006: 40). Hablamos entonces de una construcción refractaria de autenticidad, si se invoca a la necesidad de artificialidad viril del varón decimonónico. Frida Kahlo como mujer se plasma estéticamente en el ejercicio de su dolor en la práctica espiritual mediante el dispositivo estoico. Los escépticos, estoicos y epicúreos aceptan la analogía entre filosofía y medicina. Estas escuelas aceptan la cercanía entre ellas, pero discutirían cómo se da tal cuidado del alma y por ende habrían desarrollado diferentes técnicas o procedimientos, llamados 'ejercicios espirituales', Pierre Hadot (2006). Un ejercicio espiritual lleva a la Remisión tal como lo advierte Heidegger, como Verwindung -un extenso remitirse de una enfermedad- hacia el tiempo en que "todos fuimos mujeres", en el que éramos ambiguos ante la imprecisa naturaleza del primer mestizaje, en la que nos confundíamos con amenidad. La superación característica de la dialéctica es, en el pensamiento débil de Gianni Vattimo, reemplazado por la idea de derrumbe o debilitamiento distorsionante Verwindung, un actitud que caracteriza a la recuperación insistente del paisaje vital "vegetal", en el sentido de que no es violento, en contraposición con la metafísica tradicional, (Vattimo 1983). La mujer como tiene que devenir-mujer, para que el hombre también lo devenga o pueda devenirlo. Cuando fuimos mujeres éramos pura vinculación indeterminada en aquel estadio en que formábamos parte de un primer mestizaje, de un amasijo inicial indiferenciado. Este uso de tecnologías del yo, desde una hermenéutica del sujeto, es lo que realiza Kahlo en una "pintura de sí" (Foucault, 1988: 16-49) que se aleja de lo urbano. Por otra parte le permite realizar por sus propios medios operaciones en sus propios cuerpos y almas, pensamientos, conducta y forma de ser, para para alcanzar el estado de control de sí.

\section{La ambigüedad en la frontera.}

La frontera entre México y Estados Unidos manifiesta un linde entre un mestizaje y el otro, es decir, entre lo paisajístico informe, y el paisaje urbano, cuya energía depende del subsuelo mexicano. En la obra de Kahlo, que describe la frontera entre México y Estados Unidos, esa condición se observa en la alimentación de las raíces. Si hacemos descripción de "Autorretrato en la frontera entre México y los Estados Unidos", nos damos con un cuadro que fue pintado poco después de su estancia en Detroit (Michigan) junto con su marido (De Toro, Ceballos, 2014). La amistad con Wilhelm Valentiener durante su estancia en Detroit en 1932 permitió que Frida accediera al arte vanguardista. El resultado de la integración de las múltiples influencias en la obra de Kahlo es declarado como un "realismo figurativo" con elementos fantásticos y el uso de montajes y discontinuidades entre elementos indígenas e industriales (Westheider, 2006).

Figura 2. Autorretrato en la frontera entre México y los Estados Unidos. 1932. Óleo sobre metal de 31 x $35 \mathrm{~cm}$.

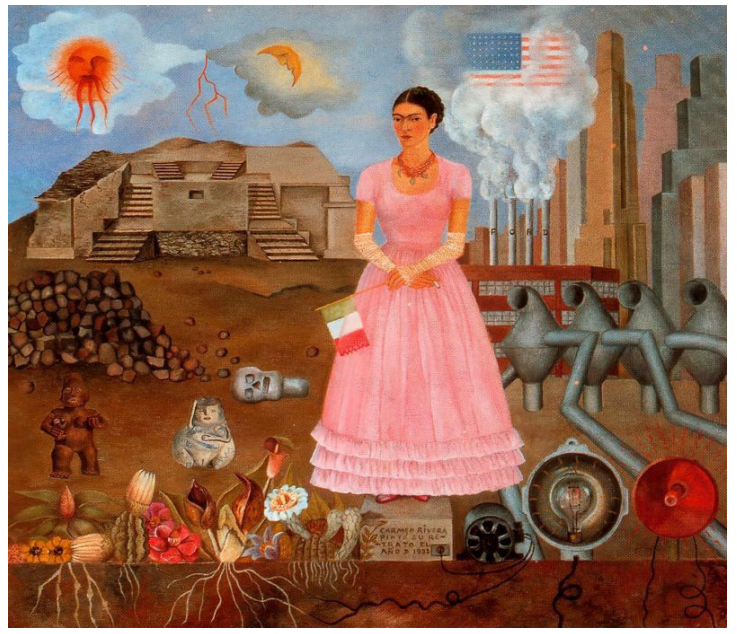

Fuente: Fotografia tomada por el autor.

Frida Kahlo permanece en la ambigüedad cuando pinta "Autorretrato en la frontera entre México y los Estados Unidos". De pie, desde su vestido rosa, cruza los brazos. Sostiene con su mano izquierda una pequeña bandera mexicana y maniobra un cigarro encendido con la mano derecha. Hay razones para entender su postura Erguida entre la tierra profunda y la cultura industrial, aunque anticipadamente a ese quebrantamiento. Frida actúa aquí como la "mujer fronteriza", entre dos mestizajes: el fronterizo de sus raíces, México, y el fronterizo territorio con progreso de Estados Unidos, que se alimenta en modo rizomático del mestizaje de la tierra mexicana. Bajo la tierra los cables fabriles se vinculan horizontalmente a los rizomas de los vegetales típicos. Hay una retroalimentación entre ambas culturas, entre diferentes energías. Una composición de contactos subterráneos horizontales que no tienen ni sujeto ni objeto, cambian de naturaleza a medida que au- 
mentan sus conexiones. Frida en este autorretrato está fragmentada por la cultura política entre la quietud precolombina y la industria humeante. El zócalo sobre el que está parada marca el límite ambiguo entre ambos estilos de vida. El paisaje de México está predominado por los colores de la tierra. Las flores con sus raíces visibles ocupan el primer plano. Dos ídolos de la fertilidad y una calavera en el medio personifican el ciclo vital. Más atrás, las antiguas deidades mexicanas, aludidas en el sol y la luna, coronan las desolaciones de un templo. El paisaje de Estados Unidos de Norteamérica, a la derecha, enrarece el devenir por la profundidad femenina de América. Los rascacielos verticales se encuentran en el lugar simétrico a la pirámide de Teotihuacán. En el subsuelo el variado mundo vegetal del primer plano mexicano ha sido sustituido, por artefactos eléctricos cuyos cableados se asemejan a raíces, mientras que los símbolos del ciclo vital se ven representados por maquinarias industriales, cuya contaminación vertical intoxica la bandera de Estados Unidos. Un pequeño generador de corriente en el suelo norteamericano obtiene energía de las raíces de la "vegetalidad mexicana" y se conecta al zócalo en que sobre el que se eleva Frida. Ella es el único punto de contacto entre los dos mundos (Moscato, 2015). El cuadro propone una inmediación energética entre la pobreza ancestral como fuente atávica del sur y el progreso urbano, que se sustenta bajo la superficie, semejante al vegetal barbárico que nutre a lo carnívoro.

\section{Discusión.}

La obra de Frida Kahlo no ha sido modificada. No obstante, como exponente americana y personaje universal necesita intentar una comprensión artística que se ha tardado y se tardará. Así como hay dos formas de vida tan extremadamente distintas en cada lado de las fronteras, también hay dos Fridas que en su obra de arte se evidencian. Ambas son divididas por elementos crueles como la columna jónica resquebrajada, que separa el cuerpo Frida desde su accidente pero también que la penetra de modo vertical quebrándola en dos mitades ("La Columna Rota", 1944). Hay una Frida cuya vida está penetrada y parcelada por la cultura. América tiene en su seno algo más que la pretensión de unidad latinoamericana. Es ni más ni menos que la frontera y la convivencia entre la
América occidental e imperial y la Latinoamérica indígena. En el caso de su vida entre Estados Unidos y México, la frontera tiene su altar en el límite donde Frida se instala. No es una situación en la que moderadamente se pasa de un modelo a otro sino un choque que es tan impetuoso como el sufrido en su adolescencia, que la atraviesa del mismo modo, como parece haber sentido en su cuerpo y, de hecho, ha sido así. En este caso su pintura nos hace ver las ambigüedades propias de América. La colisión cultural, en Frida Kahlo, es desde siempre, según lo estamos manifestando, algo que América vive entre el Estar y el Ser. No es un estadio de linealidad donde una situación civilizada ha superado a otra, sino una mixtura de cada lado que no terminan de fusionarse, a la que Kusch menciona como cobarde ambigüedad. José Tasat (2013) menciona, ajeno a la estética de Frida Kahlo, pero cercano a la filosofía de Kusch, cómo es este límite desde una geo-culturalidad, entre la tensión mestiza, de lo sagrado y lo profano. Es cuando en la noción de Occidente se refugia la ciencia, el desarrollo y la innovación, mientras en América, se refugia la magia. Existen dos mestizajes en convivencia. Tal como concibe el pensador argentino Rodolfo Kusch, es algo que le es propio al continente. Se expresaba en la vida indiferenciada en una relación compleja sin el imperio del Ser. Actualmente se expresa en una convivencia en la que formalmente imperan los conceptos del mestizaje entre lo bárbaro y lo civilizado. Tal cual puede observarse en la obra de Frida Kahlo, en la ciudad es atravesada por ese segundo mestizaje. La poliomielitis, y un muy grave accidente de tránsito le devuelven la posibilidad de hacer un culto de sí horizontal, atada a cordones vegetarianos que le reabren las aduanas de aquel primer mestizaje. El arte de Frida Kahlo en sus obras rompe la moldura de la tradición del arte político por el que está influida, que cultivaba Diego Rivera. Un autorretrato de Kahlo puede ser lo que los zapatos de Van Gogh para Heidegger. Intrigado por el cuadro, Heidegger le dedicó una lección magistral en la Universidad de Heidelberg (sur). Le sirvió de plectro para elaborar una tesis sobre El origen de la obra de arte. Heidegger advierte que el artista cumple el hecho de producir o traer aquí -hacia a lo urbano del ente- obras, lo cual acontece como traer de antemano, hace que llegue la entidad a su presencia a partir de su aspecto (Heidegger, 1950). Buscamos en este artículo el arte para hablar de 
filosofía, no solamente de Frida y su muy popular vida. Así como Heidegger pregunta por un par de zapatos de Van Gogh, en América puede preguntarse sobre el arte de la mujer que permanece acostada cuando pinta. Kahlo ha girado en torno al concepto de diversidad, en cuanto territorio de dolor incomunicado del primer mestizaje. Percibe la necesidad de reconocimiento de la territorialidad de su cuerpo, como añoranza del primer mestizaje, tal cual observamos en la fusión con lava de su cuerpo. Pinta para verse a sí misma, para hallarse como "Estar territorial" arrebatado. No hay contactos precedentes entre Rodolfo Kusch y Frida Kahlo entre pensamiento $\mathrm{y}$ arte. El presente es un intento de vincularlos. Reconocemos en ambos la intención de remisión a lo que asoma siempre en América. Aunque parezca que ha sido un período superado, aún no lo es. $\mathbf{C}$

\section{Referencias bibliográficas.}

Amezcua, M. (2007). Laboratorio de Investigación Cualitativa. Fundación Index, Granada, España. Index Enferm vol.13 no.46 Granada oct. 2004 http://scielo.isciii.es/scielo.php?script=sci_ arttext\&pid=S1132-12962004000200014 Arendt, H. (1956). Between past and future. Penguin Publishing Group.

Arriola, J. (2013). Crítica Contemporánea. Revista de Teoría Política, No3 Dic. 2013 - ISSN 1688-7840 Jonathan Arriola.

Artola, I. (2007). Isla de Arriaran. Revista cultural y científica. Número 30, 2007.España.

Balladares Burgos, J., Avilés Salvador, M. (2014). "El 'Estar-siendo' como estructura existencial y como decisión cultural americana". Revista Sophia. Universidad Politécnica Salesiana del Ecuador.

Beuchot, M. (2003). El barroco en el neobarroco actual. Devenires. Revista de Filosofía y Filosofía de la Cultura, México, Facultad de Filosofía "Samuel Ramos" de la Universidad Michoacana de San Nicolás Hidalgo.

Beuchot, M. (2005). Interculturalidad y derechos humanos. Siglo XXI/UNAM, México, 2005.

Cepeda, J. (2016). Entre Quetzacoatl y Pishimisak: Ontología existencial del Abya Yala. De Kusch y el pensamiento originario. http://repository.usta.edu.co/handle/11634/2970.

Cepeda, J. (2017). Ontología De Rodolfo Kusch Mandala Ontológico De La Filosofía Latinoame- ricana Juan Cepeda H. Universidad Santo Tomás. Facultad De Filosofía Y Letras Doctorado En Filosofía Bogotá, D.C. 2017. Página 133.

Corbetta, S. (2014). "Kusch y un 'pensar América' seducido por la barbarie" en Ferrás, G. (edit.). Civilización y barbarie: textos, cuerpos y miradas de la "otredad" desde el horizonte hispanoamericano. Córdoba, Báez Ediciones.

Deleuze, G., Guattari, F. (1972). Capitalisme et Schizophrénie 1. L'Anti-CEdipe. Collection Critique. Les Editions de Minuit Paris.

De Toro, A., Ceballos, R. (eds.) (2014). Frida Kahlo 'revisitada': Estrategias transmediales - transculturales - transpicturales. Hildesheim;Zürich; New York: Georg Olms Verlag.

Dominguez Romero, N. (2014). Frida Kahlo: el autorretrato como solución. V Congreso Universitario Internacional Investigación y Género, [libro de actas]. Facultad de Ciencias del Trabajo de la Universidad de Sevilla.

Fernández, A. (1998). Dioses Prehispánicos de México: Mitos y Deidades Del Panteón Náhuatl. Panorama Editorial. México.

Fischer Pfaeffle, A. (2003). Devenires, cuerpos sin órganos, lógica difusa e intersexuales. Sexualidades migrantes. Diana Maffia compiladora. Gráfica Integral, Buenos Aires.

Hadot, P. (2006). Ejercicios espirituales y filosofia antigua, Madrid: Ediciones Siruela.

Heidegger, M. (1950). Holzwege. Ed. Klostermann. Francfort.

Heidegger, M. (1963). Sein und Zeit. Tübingen, Max Niemeyer Verlag.

Hernández Otañez, J. (2016). La hermenéutica analógica y su analogía con el Arte. Murmullos filosóficos. UNAM. año V, 2016, N10. UNAM. México. Hullot-Kentor, R. (2010). What Barbarism Is? School of Visual Arts, New York City. The Brooklyn Rail. Critical Perspectives on Arts, Politics and Culture, 2010. https://brooklynrail. org/2010/02/art/what-barbarism-is

Kusch, R. [1953] (1997). La Seducción de la Barbarie: análisis herético de un continente mestizo. Obras completas, Tomo I. Rosario: Editorial Fundación Ross.

Kusch, R. (2000). Geocultura del Hombre Americano. Obras completas, Tomo III. Rosario: Editorial Fundación Ross.

Kusch, R. [1962] (2003). América Profunda. Obras completas. Tomo II. Rosario, Argentina: Ross.

Moscato, C. (2015). Autorretrato entre la frontera de México y los Estados Unidos. Frida Kahlo. 
Viernes 6 febrero 2015. Diario el 9 de Julio. http:// www.diarioel9dejulio.com.ar/noticia/50222

Mignolo, W. (2010). Introduction. En Rodolfo Kusch. Indigenous and popular thinking in América. Durham: Duke University Press, 2010. XV-LIV. Ortoll, S., Ramírez, A. (2003). Frida Kahlo. Retrato de la artista como esposa empresaria. Desacatos. Revista de Ciencias Sociales, núm. 11, primavera. pp. 120-130.

Ramos de Francisco, C. (2008). Frida Kahlo: Enfermedad, Sentimiento y Arte en su Obra Pictórica. IX Congreso Nacional de Historia de la Medicina. Caracas. Octubre, 2008.

Rajchman, J., West, C. (1985). Post-analytic philosophy, Nueva York, Columbia University Press, 1985, pp. 3-19.

Rorty, R. (1989). Contingency, Irony, and Solidarity. Cambridge University Press.

Ruvituso, C. (2017). (Universidad de Rostock, Alemania). "Filosofía y americanismo en Francisco Romero y Rodolfo Kusch". Ideas N5 Revista de filosofía moderna y contemporánea. RAGIF. Red Argentina de Grupos de Investigación en Filosofía. Buenos Aires.

Scannone (2009). 59,73. Desde la Analéctica Teológica. Teología y Vida, Vol. L Facultad de Teología. Universidad Católica de Argentina. La filosofía de la liberación: historia,características, vigencia actual.

Tasat, J. (2013). El pensamiento de Rodolfo Kusch, Estar siendo en América Latina: "un pensamiento que conlleva la esperanza de otro horizonte humano". Centro de Estudos Sociais. Universidade Coimbra.

Vargas Llosa, M. (2002). Resistir Pintando -el lenguaje de la pasión. Madrid. Suma de Letras.

Vattimo, G. (1983). Il pensiero debole (1983). Editado por G. Vattimo y P. A. Rovatti, Milán, Feltrinelli. Viveros Espinosa, A. (2016). 215-232. Enfoques Sobre La Filosofía De Rodolfo Kusch. El Método, Lo Popular y El Indígena como Horizontes de Pregunta En La Filosofía Americana. Revista Alpha/n42/ Chile.

Westheider, O. (2006). Frida Kahlo und die Avantgarde in Europa. Pittura Metafísica. Dadaismus, Neue Sachlichkeit und Surrealismus, en Idem. Frida Kahlo. Exposición y Catálogo (Ausstellung und Katalog). Bucerius Kunst Forums, Hamburg, 15 de junio al 17 de septiembre. Múnich: Hirmer. 